\title{
Alternative refrigerants in vapour compression refrigeration cycle for sustainable environment: a review of recent research
}

\author{
V. W. Bhatkar · V. M. Kriplani · G. K. Awari
}

Received: 20 August 2011/Revised: 8 November 2011/ Accepted: 21 March 2012/Published online: 2 March 2013

(C) Islamic Azad University (IAU) 2013

\begin{abstract}
Vapour compression refrigeration is used in almost $80 \%$ of the refrigeration industries in the world for refrigeration, heating, ventilating and air conditioning. The high-grade energy consumption of these devices is very high and the working substance creates environmental problems due to environmental unfriendly refrigerants such as chloroflurocarbons, hydrochloroflurocarbons and hydroflurocarbons. Heating, ventilating, air conditioning and refrigeration industries are searching for ways to increase performance, durability of equipments and energy efficiency in a sustainable way while reducing the cost of manufacturing. With the present refrigerants, environmental problems such as ozone layer depletion, global warming potential, green house gases and carbon emission are increasing day by day. In this paper, the popular refrigerant is thoroughly studied experimentally and recommendations are given for alternatives such as carbon dioxide, ammonia and hydrocarbons and new artificially created fluid, HydroFluoro-Olefin 1234yf by DuPont and Honeywell which exhibit good thermo-physical and environmental properties and will be commercialized in the near future.
\end{abstract}

\footnotetext{
V. W. Bhatkar $(\bowtie)$

Research Scholar, Department of Mechanical Engineering, G.H. Raisoni College of Engineering, Hingna Road, Nagpur, Maharashtra 440016, India

e-mail: vijay_bhatkar2001@yahoo.com

V. M. Kriplani

Department of Mechanical Engineering, G.H. Raisoni College of Engineering, Hingna Road, Nagpur,

Maharashtra 440016, India

G. K. Awari

Tulsiramji Gaikwad-Patil College of Engineering and

Technology, Mohgaon, Wardha Road, Nagpur 441108, India
}

Keywords Carbon emission · Environment . Global warming

\section{Introduction}

The industry that never lags behind in its contribution to the social, economic and environmental pillars of sustainable development is refrigeration. The refrigeration industry is an indicator of the development of the country. On the other hand, it is important to minimize emission of refrigerants to reduce the impact on the environment and to reduce energy consumption of refrigerators and air conditioners (Awad et al. 2007; Fernando et al. 2008a, b). The first generation of refrigerants was introduced in the 1830 s, with the invention of the vapor-compression machine by Perkins. For nearly 100 years (1830-1930) whatever worked as a refrigerant [e.g. carbon dioxide $\left(\mathrm{CO}_{2}\right)$, ammonia $\left(\mathrm{NH}_{3}\right)$, carbon tetrachloride $\left(\mathrm{CCl}_{4}\right)$, hydro carbons $(\mathrm{HCs})$, water $\left(\mathrm{H}_{2} \mathrm{O}\right)$, etc.] was used for refrigeration and air conditioning (Perkins 1834). Most of them were toxic, flammable or both. Some refrigerants, such as sulfuric (ethyl) ether, ammonia and hydrocarbons were highly reactive. Many accidents occurred as the primary goal was only to provide refrigeration at that time. DuPont's "Freon" products, chlorofluorocarbons, CFC-11, CFC-12, and hydrofluorocarbons, HCFC-22 were probably the most well-known fluorocarbon refrigerants for the refrigeration and air-conditioning industry. CFCs were the refrigerants of choice for refrigeration and air conditioning system from the inventions in the 1930s until their eventual phase out in the 1990s in accordance with the Montreal Protocol. For almost half a century, fluorocarbons have been the dominant choice of refrigerants until they were associated with the "ozone hole" story-the first global environmental problem identified by Molina and 
Rowland (Philip 2008). Since then, a landmark international treaty, i.e. the Montreal Protocol was set up in 1987 to protect the ozone layer. Chlorinated and brominated refrigerants, along with similar solvents, foam blowing agents, aerosol propellants, fire suppressants and other chemicals are scheduled to be phased out. Ozone depletion was the only environmental concern at that time. But due to environmental concerns like ozone depleting potential (ODP), increase in global warming potential (GWP), green house gases (GHG), carbon emissions, CFCs were banned and thus further research continued. Global warming potential is a relative measure of how much heat can be trapped in the atmosphere. It is a relative scale which compares the gas in question to that of the same mass of carbon dioxide whose GWP is by definition 1. GWPs are calculated as the ratio of the radiative forcing that would result from the emissions of $1 \mathrm{Kg}$ of a green house gas to that from emission of $1 \mathrm{Kg}$ of carbon dioxide over a period of time, (UNEP 2000; Daniel 2007) (Table 1).

The second generation was distinguished by a shift to fluoro chemicals for safety and durability as $\mathrm{HCs}$ had some accidents, so CFCs such as R-11 (CCl3F), R-12 (CCl2F2) and HCFC, R-22 (CHClF2) were used and serve the refrigeration and air conditioning industry for a long time. Third generation was related to ozone depletion protection. The chlorine atom in CFCs and HCFCs reacts with ozone molecules and destroys ozone layer in the stratosphere, nearly $11 \mathrm{~km}$ from the Earth surface, which acts like a umbrella for the planet by absorbing ultraviolet (UV) rays from the Sun. The Vienna Convention and resulting
Montreal Protocol forced the abandonment of ozone depleting substances (ODSs) for developed countries, to phase out CFC refrigerant use in new equipment by 1996 and for developing countries by 2010 , requiring phase out of R-22 by 2010 in new equipment and then banning all HCFC use in new equipment by 2020 . Fourth generation is now related to global warming (Calm 2008) (Fig. 1).

The Kyoto Protocol, pursuant to the United Nations Framework Convention on Climate Change (UNFCCC), sets binding targets for greenhouse gas emissions based on calculated equivalents of carbon dioxide, methane, nitrous oxide, HFCs, perfluorocarbons (PFCs) and sulfur hexafluoride. The European Parliament set the timing with a directive that bans fluoro chemical (F-Gas) refrigerants having GWPs exceeding 150 for 100 years integration in air conditioners for new model automobiles effective from 2011 and for all new automobiles starting in 2017. The immediate effect of these measures is to ban R-134a (C2H2F4) which is most widely used in the world as a refrigerant in mobile air conditioners. Due to the potential global warming caused by HFC refrigerants, there is an increasing universal interest to research environmentally friendly fluids in refrigerants and alternative approaches to the traditional dry expansion (DX) refrigeration system (Tony 2001; Cavallinia et al. 2003). These refrigerants include ammonia, carbon dioxide, hydrocarbon, R-152a and HFO-1234yf. The major drawbacks of these refrigerants are their potential flammability and other safety hazards. One way to overcome this issue is to use the new refrigerants in conjunction with a secondary loop

Table 1 Environmental effects of refrigerant

\begin{tabular}{|c|c|c|c|c|}
\hline Type & Refrigerants & ODP & GWP (100 years) & $\begin{array}{l}\text { Atmospheric lifetime } \\
\text { (years) }\end{array}$ \\
\hline \multirow[t]{2}{*}{$\mathrm{CFCs}$} & CFC-11 & 1 & 4,680 & 45 \\
\hline & CFC-12 & 1 & 10,720 & 100 \\
\hline \multirow[t]{3}{*}{$\mathrm{HCFCs}$} & HCFC-22 & 0.05 & 1,780 & 12 \\
\hline & HCFC-141b & 0.11 & 630 & 9.3 \\
\hline & $\mathrm{HCFC} 142 \mathrm{~b}$ & 0.065 & 2,000 & 17.9 \\
\hline \multirow[t]{5}{*}{ HFCs } & HFC-32 & 0 & 650 & 4.9 \\
\hline & HFC-125 & 0 & 2,500 & 29 \\
\hline & HFC-134a & 0 & 1,320 & 14 \\
\hline & HFC-407C [HFC32/125/134a (23/25/52 wt \%)] & 0 & 1,674 & 29 \\
\hline & HFC-410A (HFC-32/125 (50/50 wt \%)) & 0 & 1,997 & 29 \\
\hline \multirow[t]{4}{*}{ Natural refrigerants } & Carbon dioxide (R-744) & 0 & 1 & 0 \\
\hline & Ammonia (R-717) & 0 & 0 & 0 \\
\hline & Isobutene (HC-600a) & 0 & 3 & 0 \\
\hline & Propane (HC-290) & 0 & 3 & 0 \\
\hline New & HFO-1234yf & 0 & 4 & 0 \\
\hline
\end{tabular}

Source: montreal protocol science assessment of ozone depletion 2002

R-407C and R-410A are blend refrigerants of R-134a, R-32 and R-125. Highest value among the components (i.e. R-125) is considered for the atmospheric lifetime 
Fig. 1 Phases of refrigerant

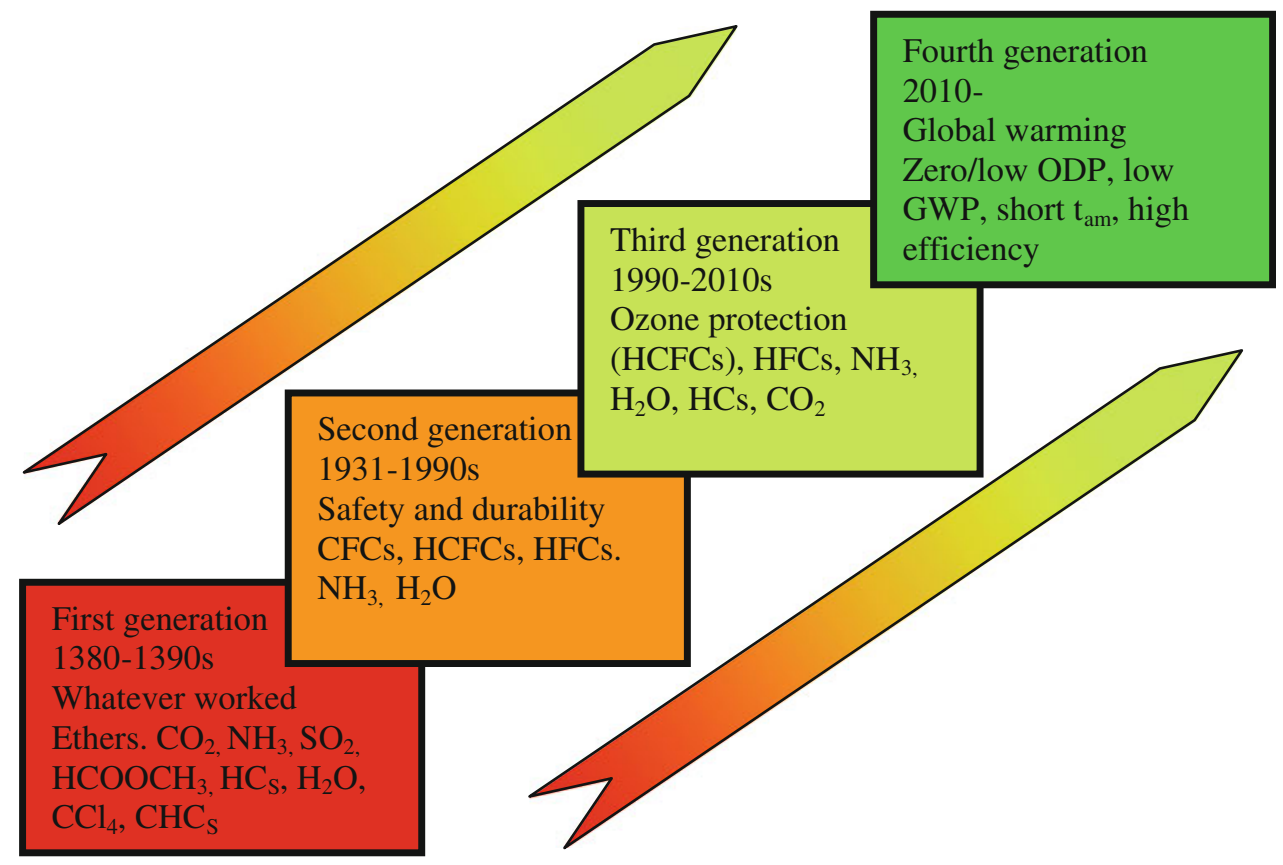

refrigeration system (Kai et al. 2010). Additional benefits of the secondary loop refrigeration system are refrigerant charges, leakage reduction, potential maintenance simplification and low operating cost.

\section{Refrigerant charge reduction techniques}

As the refrigerant charge in the refrigerant system reduces the chances of leakages are less; so less impact of refrigerant on the environment. Micro channel condensers are used to reduce the cost of the refrigeration equipments and also to reduce the charge of the refrigerant. These heat exchangers consist of serpentine fins that are brazed to multi-port tubes with internal microchannels (GarciaCascales et al. 2010). Even though apparently better heat transfer characteristics of microchannel heat exchangers exist, microchannel heat exchangers are not commonly used in residential air-conditioning systems because round tube plate fin (RTPF) heat exchangers have a cost advantage, which is one of the most critical factors of commercial products (Park and Hrnjak 2008). The flow regimes observed during an experiment in the microchannels are dependent on several factors, such as flow rates, properties of the fluids used, channel inclination with respect to the horizontal, as well as channel geometry and size (Pehlivan et al. 2006). Classification of micro channels based on fixed channel hydraulic diameters is as follows: microchannels $(1-100 \mu \mathrm{m})$, mesochannels $(100-1000 \mu \mathrm{m})$, macro-channels $(1-6 \mathrm{~mm})$ and conventional channels $(>6 \mathrm{~mm}$ ) (Wei and Zan 2010). The ability to produce tubes with external or internal fins and with smaller wall thicknesses allows higher heat transfer area per unit volume of a tube.
Therefore, mini- and microchannel tubes are ideal for use in compact and light weight heat exchangers (Fernando et al. 2008a, b). Especially, R410A is appropriate for microchannel heat exchangers because of its higher working pressure and lower pressure drop characteristics, which can solve the mal-distribution problems of the fluid in microchannel heat exchangers (Yun et al. 2006). Development of compact and high-performance heat exchangers is one method for system efficiency improvement of vapor compression refrigeration systems and to reduce their environmental impact (Zhaogang et al. 2009). The energy consumption of these units depends on the coefficient of performance (COP), which is improved by decreasing the condensing temperature. An experimental and theoretical investigation was performed to evaluate the application of evaporative condenser in residential refrigerator. Results shows 10-20\% of saving in electrical energy using evaporative condensers (Nasr and Salah Hassan 2009). This work focused on laminar flow $(69<\operatorname{Re}<800)$ within rectangular microchannel with hydraulic diameter from 106 to $307 \mu \mathrm{m}$ for single-phase liquid flow. Over- or under-estimation of pressure drops was caused by increased pressure drop in entrance region of the channel (Park and Punch 2008). All devices with characteristic dimensions between $1 \mu \mathrm{m}$ and $1 \mathrm{~mm}$ are called micro devices. The experimental data obtained compared with rectangular microchannels machined in an aluminium plate and bonded with a plexiglass plate with the data obtained using microchannels etched on a silicon wafer and bonded with a Pyrex cover (Gian Luca Morini 2004). The design of refrigeration systems thus means reducing the released refrigerant charges (direct greenhouse effect), at the same time as reducing 
the energy consumption of the systems (indirect greenhouse effect). From a global viewpoint, the technical options favourable to charge reduction are (i) the use of refrigerating systems with secondary refrigeration rather than direct refrigeration, (ii) the use of direct expansion fed evaporators rather than flooded evaporators, (iii) the use of hydrocarbon, ammonia or $\mathrm{CO}_{2}$ like refrigerant, and (iv) the use of compact exchangers. However the design of the systems has to consider both the charge reduction and its impact on the indirect greenhouse effect (Poggi et al. 2008). According to the experimental results, the pressure drop increases with increasing the mass flux, but decreases with increasing the saturation temperature, and the heat flux has no significant effect on the pressure drop (Jatuporn Kaew-On and Somchai 2009).

\section{Hydroflurocarbon, HFC (R-134a)}

Today, global warming is receiving more and more attention. It is believed that global warming has caused climate change. Presently, HFC R-134a, is used in almost all of the commercial applications as well as for household purposes. The alarming increase in atmospheric concentration of HFC-134a suggested careful considerations of not overusing any single compound for substituting ozone depleting and global warming substances. It must be phased out soon according to Kyoto Protocol due to its high GWP of 1300 . Its impact to the environment is far more significant than ozone depletion. The higher GWP due to R-134a leads to identify a long term alternative to meet the requirement of system performance, refrigerant-lubricant interaction, energy efficiency, environmental impacts, safety and service. Refrigerant gases are heavier than air and remains on the earth surface for longer time, sometime for decades or even more and hence sun rays are not reflected back to the space from the earth and as a result increase in temperature of the earth surface leads to global warming (Philip 2008). Due to increase in temperature of the earth, adverse effects like polar ice is melting so floods are occurring, sea level is rising, draught in some regions, severe infections, skin diseases, adverse effects on animal and plants growth, etc. are started (Roshan et al. 2010). Looming on the horizon is the possibility that HFCs for stationary applications might be next on the list to phase out. Already, many countries tax HFCs at higher level to discourage use. So there is an urgent need to find an alternative to the conventionally used refrigerant, R-134a. Sustainable buildings, whole buildings or green buildings have received more attention nowadays and a lot of building owners are willing to obtain proper certification as a branding effect (Clito and Afonso 2006). Different green building rating systems have been investigated, especially regarding the environmental assessment to refrigerant selection.

\section{Materials and methods}

Next generation of refrigerants

There is no general rule governing the selection of refrigerants. Individual refrigerants have different thermo-physical properties and hence different performance which is also strongly influenced by system design and operating conditions. Optimum selection is not easy; one needs to compare the alternatives properly and systematically. A universal comparison method has not been established (Rotchana 2009). Available methods used to compare refrigerant performances are first thermodynamic analysis which is simple but does not take into account component characteristics, secondly detailed simulations which is time-consuming, accuracy depends on assumptions and correlations used and lastly experimental measurements in which only limited numbers of refrigerants could be tested at a time in a given system (Daniel 2007) (Table 2).

A simple but reliable model is required (Daniel 2007). There are five classic criteria such as thermo-physical properties, technological and economic aspects, safety and environmental factors; however, in addition to these criteria, others have to be considered such as local regulations and standards. The best approach when presenting evolution and trends is certainly the application approach. Depending upon the following eight applications the refrigerants are selected: domestic refrigeration, commercial refrigeration, industrial refrigeration (storage, food industry, other industrial applications), land refrigerated transport, marine refrigerated transport, unitary air conditioning and heat pumps, water chillers and mobile air conditioning (Didier Coulomb, Director of the IIR 2008). The refrigeration sector has taken initiative in the field of alternative to ozone depleting refrigerants; CFCs, HCFCs and green house refrigerants are also an important breakthrough. Among non HFC refrigerants developed to replace fluorocarbon refrigerants, the focus is again on natural refrigerants such as ammonia, carbon dioxide,

Table 2 Ideal cycle efficiency comparison: influence of refrigerant selection

\begin{tabular}{llll}
\hline Refrigerant & COP & KW/ton & HP/ton \\
\hline CFC-11 & 4.895 & 0.718 & 0.963 \\
CFC-12 & 4.497 & 0.782 & 1.048 \\
HCFC-22 & 4.444 & 0.791 & 1.061 \\
HFC-134a & 4.376 & 0.803 & 1.077 \\
R-717 & 4.643 & 0.757 & 1.015 \\
R-290 & 4.293 & 0.819 & 1.098 \\
R410 A & 4.137 & 0.850 & 1.140 \\
\hline
\end{tabular}

Source: ASHRAE handbook of fundamentals, $20 \mathrm{~F}$ evaporating and $105 \mathrm{~F}$ condensing temperatures (2007) 
hydrocarbons such as isobutane (R-600a) and propane (R-290a) which are also having the potential of being a bit more energy efficient and the refrigerants which are having zero ODP, very low GWP, high efficiency and new refrigerant created by chemical giants, DuPont and Honeywell, such as Hydro-Fluro-Olefins (HFO-1234yf, CF3CF= $\mathrm{CH} 2$ ) which is in the research phase and will be commercialized soon all over the world. Refrigerant impact on the atmosphere can be reduced by considering various nonconventional methods of refrigeration such as thermoelectric, magnetic, acoustic, etc. (Shenzhen 2006).

Following are the important properties of the various alternative refrigerants.

Hydrocarbons (Isobutane and propane)

Hydrocarbon refrigerants are the best choice refrigerants, when considered from an "economical" and "environmentally sustainable perspective". Hydrocarbons are natural substances which have excellent thermodynamic properties and good miscibility properties with inexpensive mineral oil. They have zero ODP, negligible GWP and inherently good efficiency. They are highly flammable and this restricts the way in which they can be used. The two main hydrocarbons used as refrigerants are isobutane (in refrigerators) and propane (in small commercial appliances and residential heat pumps). Hydrocarbon, isobutane (R-600a, C4H10) and propane (R-290, C3H8) are non-toxic. United States and Canada place restrictions on the use of this flammable gas, but it is used in over 300 million household freezers across Europe, Japan, Russia and China (Emma 2009). Notably isobutane and its blends have displaced R-12 and later R-134a and now dominate in domestic refrigerators in Europe, but not in North America and especially not in the United States. Typical refrigerator sizes are larger in the USA than in Europe, but are more comparable to those in Japan and Korea where isobutane use also is increasing in refrigerators and vending machines. Isobutane is unlikely to be appropriate for use in large applications such as supermarket freezers as a result of its flammability. The US approach in this respect is noteworthy as government/industry partnerships have led to large energy savings. Certification programs provide the means by which manufacturers test and assign energy efficiency ratings to air conditioners and heat pumps. In Europe, energy labeling of new refrigerators has brought about significant energy savings, average energy savings of $15 \%$ have been achieved in new refrigerators purchased between 1992 and 1995 in Germany and similar energy savings are being achieved in neighboring countries. The advantage of using hydrocarbons as refrigerant in vapour compression is that energy efficiency increases by around $15-20 \%$ and also its density is $40 \%$ of the HFCs; so charge is reduced (Mohanraj et al. 2009). According to various research papers, if the refrigerant charge in the refrigerator is below $50 \mathrm{gm}$, the chances of explosion are nil. So use of hydrocarbon as refrigerant in small capacity commercial as well as household refrigerators again increase day by day. Also the mineral oil which is used for CFCs, HCFCs and HFCs is also suitable with HCs and can be used as compressor oil in propane, isobutane refrigerant systems. Flammability and explosion hazards generally impede hydrocarbon use in large capacities, except in chemical process applications for which the processes themselves present greater hazards and already are protected (Kondo et al. 2009).

\section{Ammonia (R717)}

Ammonia has been established as the pre-eminent industrial refrigerant for over 125 years and is used in a wide variety of applications throughout the world, especially in the industrial field. It is one of the oldest refrigerants and remains the refrigerant of choice in industrial systems and especially for food and beverage processing, which often require large internal volumes and flexibility in system modification as well as storage. It has zero GWP and ODP. It is a hazardous substance, but used safely around the world in large-scale industrial cooling systems such as food processing and building air conditioning. Ammonia is being introduced in indirect systems in commercial fields and air conditioning chillers (Fernando et al. 2008a, b). Physical properties of ammonia make it very energy efficient as a refrigerant. Although it is acutely toxic at relatively low concentrations, deaths from exposure to ammonia are extremely rare, principally because it has an unpleasant smell even at very low safe concentrations. The advent of the screw compressor, which overcomes the high discharge temperature problems and the introduction of plate type heat exchangers containing very low volumes of refrigerant, make it possible to design very simple lowcharge ammonia systems. Due to its environmentally friendly characteristics, this refrigerant may be considered for wider use provided that safety issues and staff training are well handled. Ammonia's interest renewed in Europe and especially so in Northern Europe. Concerns with its flammability and to a lesser extent also skin corrosively, limit broader acceptance in other locations, particularly in warmer climates commonly using larger chillers in proximity to densely occupied spaces. The Kyoto Protocol of the United Nations framework convention on climate change calls for reductions in emissions of six categories of green house gases including refrigerants which is the vital working substance in refrigeration, air conditioning system and heat pumping systems. So focus is again on ammonia as a natural refrigerant. 
Carbon dioxide (R-744)

Carbon dioxide was used as a refrigerant before the discovery of CFCs. Carbon dioxide is one of the classic refrigerants that had fallen into almost complete disuse but which is currently making a spectacular comeback, thanks in particular to its very good environmental properties. Global warming potential of $\mathrm{CO}_{2}$ is 1 , it is non-ozone depleting, non-toxic, non-flammable. $\mathrm{CO}_{2}$ operates at a higher pressure than HFC, which means it requires new system design and components. The $\mathrm{CO}_{2}$ refrigerant also has favourable thermo-physical properties such as higher values of density, latent heat, specific heat, thermal conductivity and volumetric cooling capacity, and lower value of viscosity ( $\mathrm{Ge}$ and Cropper 2009). The automotive industry now is pursuing three primary candidates to replace R-134a in mobile air conditioners, namely carbon dioxide, Hydro-Fluro-Olefin (HFO)-1234yf in direct expansion systems and R-152a in indirect ("secondary loop") systems employing an intermediate heat transfer fluid. The major objections to the use of carbon dioxide as a refrigerant are its low critical point and its high operating pressure compared with other refrigerants. Nevertheless, carbon dioxide, as a refrigerant, can be used in two distinct ways one as a supercritical refrigerant operating on a transcritical cycle, evaporating in the subcritical region and rejecting heat at temperatures above the critical point in a gas cooler instead of a condenser. A very significant number of developmental efforts are directed towards applications such as automotive air conditioning and heat pumping applications. The high operating pressures of $\mathrm{CO}_{2}$ put different constraints on the design of conventional components such as heat exchangers and compressors and as a low-stage refrigerant in a cascade system using a more conventional refrigerant such as HFC, ammonia or hydrocarbon in the high-temperature stage. Cascade carbon dioxide systems have been in use since 2000 and have developed quickly since 2004. Today more than $130-140$ such installations exist in European supermarkets and around 150 are used in agro food processes (freezing) and ice rinks. $\mathrm{CO}_{2}$ is now being adopted as a solution in retail applications (e.g. small commercial applications such as beverage vending machines) and is approaching market application in the field of mobile air conditioning. $\mathrm{CO}_{2}$ is also used as a volatile secondary fluid at low or medium temperatures with pump circulation to avoid transcritical cycles.

\section{Benefits of $\mathrm{CO}_{2}(\mathrm{R}-744)$}

Carbon dioxide concentration inside the passenger cabin/ room do not reach critical levels, due to reduced refrigerant charges $(<300 \mathrm{~g})$ so it is safe for human beings. It is nontoxic, R-744 is neither flammable nor does any decomposition products harmful to human life and has no health issue in workshops/service places. $\mathrm{CO}_{2}$ itself is cheap and readily available. Carbon dioxide use also is increasing, especially in Europe, for commercial refrigeration both as a refrigerant and in indirect hydrocarbon refrigerants. The potential applications of $\mathrm{CO}_{2}$ are numerous. One important obstacle to overcome is the cost of the construction of refrigerating equipment suitable for the high pressures involved when $\mathrm{CO}_{2}$ is used (SAE International 2008) (Table 3).

$\mathrm{CO}_{2}$ based air conditioning systems are used in industry, but none have been installed in a car, partly owing to the engineering challenges posed by $\mathrm{CO}_{2}$. One of these is the high pressures required in the system, up to 10 times those of fluorocarbon-based systems. Another is the inefficiency of operating transcritically or above a refrigerant's critical temperature (Tc). $\mathrm{CO}_{2}$ has a very low $\mathrm{Tc}$ of $31^{\circ} \mathrm{C}\left(88^{\circ} \mathrm{F}\right)$. High pressures required by $\mathrm{CO}_{2}$ result in higher "indirect" green house gas emissions (for example, from the tail pipe) than HFO-1234yf. $\mathrm{CO}_{2}$ systems must work harder to make up for the inefficiency of transcritical operation. The cost of redesign of $\mathrm{CO}_{2}$ system is another shortcoming.

Table 3 Carbon dioxide potential health effects

\begin{tabular}{lll}
\hline Concentration of $\mathrm{CO}_{2}(\%)$ & Time & Adverse effects \\
\hline $17-30$ & $0-60 \mathrm{~s}$ & Loss of controlled activity, unconsciousness, death \\
$>10-15$ & $1-3 \mathrm{~min}$ & Dizziness, drowsiness, muscle twitching, unconsciousness \\
$7-10$ & $1.5-60 \mathrm{~min}$ & Headache, increased heart rate, shortness of breath, dizziness, sweating rapid breathing \\
7.5 & $5 \mathrm{~min}$ & Significant performance decrement \\
6 & Several hours & Tremors \\
6 & $<16 \mathrm{~min}$ & Headache, dyspnea \\
6 & $1-2 \mathrm{~min}$ & Hearing and visual disturbances \\
$4-5$ & A few minutes & Headache, dizziness, increased blood pressure, uncomfortable dyspnea \\
$4-5$ & $4 \mathrm{~h}$ & Drop in body temperature $\left(1{ }^{\circ} \mathrm{C}\right)$ \\
3 & $1 \mathrm{~h}$ & Mild headache, sweating, dyspnea at rest \\
2 & Several hours & Headache, dyspnea upon mild exertion \\
\hline
\end{tabular}


Hydro-Fluoro-Olefin (HFO-1234yf)

DuPont and Honeywell jointly identified HFO-1234yf $(\mathrm{CF} 3 \mathrm{CF}=\mathrm{CH} 2)$ as a single substance as the preferred low GWP refrigerant which offers the best balance of properties and performance (Jama-Japia 2008) HFO-1234yf is the leading alternative refrigerant to replace R-134a. It has excellent environmental properties, very low GWP of four, zero ODP, favorable life cycle climate performance (LCCP) (Spatz and Minor 2008), atmospheric chemistry determined and published low toxicity similar to R-134a (Kenji et al. 2009). System performance is very similar to R-134a. Excellent COP and Capacity, no glide temperature, the only problem is HFOs are mildly flammable (Shigeo et al. 2009; Kenji et al. 2009). From both internal tests and OEM tests, HFO-1234yf has recently been approved as a class-A2L refrigerant by American Society of Heating, Refrigerating and Air Conditioning Engineers (ASHRAE). Despite carbon dioxide's appeal as a "natural refrigerant" and favorable findings in some reported bench and vehicle tests, as a single compound refrigerant, HFO-1234yf offers similar thermophysical properties to R-134a, thus minimizing equipment changes and has met criteria for stability and compatibility.

The Society of Automotive Engineers (SAE) validated that HFO-1234yf as safe for use in automotive applications. The critical temperature, critical density and critical pressure were measured by the visual observation of the meniscus disappearance and were determined to be $367.85 \mathrm{~K}, 478$ $\mathrm{kg} / \mathrm{m}^{3}$, and $3382 \mathrm{kPa}$, respectively (Tanaka and Higashi 2010). After independent review of all toxicology test results, DuPont and Honeywell have concluded that HFO$1234 \mathrm{yf}$ is safe to commercialize for use in mobile air

Table 4 Properties of HFO-1234yf and R-134a

\begin{tabular}{lll}
\hline Properties & HFO-1234 yf & R-134a \\
\hline Boiling Point $\left({ }^{\circ} \mathrm{C}\right)$ & -29 & -26 \\
Critical Point $\left({ }^{\circ} \mathrm{C}\right)$ & 95 & 102 \\
Vapour Press $\left(25^{\circ} \mathrm{C}\right) \mathrm{MPa}$ & 0.677 & 0.665 \\
Liquid Density $\left(\mathrm{kg} / \mathrm{m}^{3}\right)\left(25^{\circ} \mathrm{C}\right)$ & 1,094 & 1,207 \\
Vapour Density $\left(\mathrm{kg} / \mathrm{m}^{3}\right)\left(25^{\circ} \mathrm{C}\right)$ & 37.6 & 32.4 \\
\hline
\end{tabular}

conditioning (MAC). Furthermore, industry risk assessments of various potential exposure scenarios have also concluded HFO-1234yf is safe for use in MAC applications. HFO-1234yf flammability characteristics are much more favourable than those of hydrocarbon gases. It is far less dangerous than other hydrocarbon refrigerants. HFO-1234yf offers equivalent or lower toxicity compared to R-134a or $\mathrm{R}-12$ in terms of both human health effects and ecological effects. HFO-1234yf met all key technical customer criteria to be adopted for MAC. Various LCCP evaluations done showing LCCP benefit of HFO-1234yf compared to HFC-134a and $\mathrm{CO}_{2}$ (Spatz and Minor 2008; Minor et al. 2008) (Table 4).

HFO-1234yf is not yet a proven entity and despite the fact that it may not be commercialized for at least a year or two, it is nevertheless promoted by the chemical industry as the alternative to HFC-134a, which the car industry should wait for and switch to. This is effectively blocking the uptake of currently available, safe, environmentally friendly, efficient and low GWP, non-fluorocarbon alternatives such as $\mathrm{CO}_{2}$ mobile air conditioning systems or the commercialization of hydrocarbon MAC systems (SAE International 2008) (Table 5).

$\mathrm{CO}_{2}$ manufacturers also argue that, unlike HFO-1234yf, $\mathrm{CO}_{2}$ is proven, safe, natural and sustainable for environmental point of view (Jama-Japia 2008; Spatz Mark 2009). In a letter to German OEMs, Greenpeace Germany raises concerns over the chemical's flammability, stating that "the claim that HFO-1234yf will be an alternative is not only wrong but also life threatening; the legal consequences not calculable". Thermodynamic properties of several fluorinated propene isomers, namely: R-1225ye (E), R-1225ye (Z), R-1225zc, R-1234ye (E), R-1234yf, R-1234ze (E), R-1234ze (Z), and R-1243zf (the reader can consult ASHRAE (2008) for the naming convention for the fluorinated propene series) (Steven Brown et al. 2010).

\section{Results and discussion}

There is no ideal refrigerant in the world; so the best approach for presenting evolution and trends of refrigerant

Table 5 Comparison of HFO -1234yf and R-744

\begin{tabular}{|c|c|c|}
\hline Parameter & HFO-1234 yf & $\mathrm{R}-744$ \\
\hline Environmental impact & Lower total green house gas than either R-134a or $\mathrm{CO}_{2}$ & $\begin{array}{l}10-15 \% \text { more total global warming emission than HFO- } \\
1234 \text { yf }\end{array}$ \\
\hline Atmospheric life time & 11 days & $>100$ \\
\hline Drop in solution? & Near drop in solution & New system design is required \\
\hline $\begin{array}{l}\text { Ability to cool Auto } \\
\text { interiors }\end{array}$ & Superior performance in al climates & Less effective/efficient in hot climates \\
\hline Safety & $\begin{array}{l}\text { Safe for use in automotive air conditioning applications } \\
\text { with proper mitigation }\end{array}$ & $\begin{array}{l}\text { Safe for use in automotive air conditioning applications } \\
\text { with proper mitigation }\end{array}$ \\
\hline
\end{tabular}


is certainly the application approach. The global warming impact of refrigerating plants is about $20 \%$ direct impact due to emissions of fluorinated refrigerants (fluorocarbons) and about $80 \%$ of this impact results from indirect $\mathrm{CO}_{2}$ emissions originating in the production of the energy which is used by the plants (generally electricity). Thanks to the Montreal Protocol that was adopted in 1987, 191 countries (as of March 13, 2007) have committed themselves to measures designed to protect the ozone layer. This protocol calls for the gradual phase-out and total banning of CFCs followed by HCFCs, with a longer time frame for developing countries.

\section{Challenges in refrigerant selection}

- Reduce refrigerant leakage: International Institute of Refrigeration (IIR) highlights that the objective in this domain is to reduce refrigerant leakage by $30 \%$ by 2020. Achieving this goal involves actively pursuing actions aiming at improving refrigerant containment, intensifying research and development on promising technologies in terms of refrigerant load reductions and generally giving priority to the proper maintenance of refrigeration plants.

- Refrigerant charge reductions: It seems a promising way both to reduce refrigerant emissions and to improve the energy efficiency of systems. As an example, the use of micro channel heat exchangers makes it possible to reduce the total system load from approximately $200 \mathrm{~g}$ of R-290 refrigerant (hydrocarbon) in conventional systems to less than $130 \mathrm{~g}$ ultimately reduces the risk of flammability of hydrocarbon (Bjorn 2007; Poggi et al. 2008).

- Proper maintenance and servicing of refrigerating plants: For optimized design, it is naturally a priority as it contributes to a reduction in refrigerant emissions. Efforts made in terms of awareness and training of technicians must be pursued and should focus on generalizing certification programmes. A top priority is also the recovery, recycling, generation or the destruction of refrigerants used in refrigeration plants following standardized procedure reductions in energy consumption. The IIR considers that the objective in this domain is to reduce energy consumption by $20 \%$ by 2020 . Improving the energy efficiency of vapour compression systems is related to that of their various components (Kai et al. 2010). In this sense, very recent development of oil-free compressors offer important opportunities; the elimination of oil has the potential to significantly improve heat exchanger performance and will allow engineers to design a new generation of heat exchangers that go beyond flat tube technology, with much smaller flow channels (Yeon-Pun et al. 1997;
Garcia-Cascales et al. 2010). The advantages include better reliability, increased compactness and improved performance (Zhaogang et al. 2010; Fernando et al. 2008a, b).

- Energy consumption of these refrigerating installations contributes to $\mathrm{CO}_{2}$ emissions and consequently to global warming and reduces global energy resources. It should be remembered that refrigeration including air conditioning accounts for about $15 \%$ of worldwide electricity consumption

- Making training available to all refrigeration practitioners is a vital action in this field, particularly in developing countries that will increase the number of personnel in the years to come. Training must be extended to all staff levels such as maintenance and servicing staff, engineers and decision makers.

Refrigeration and air conditioning are important for following point of view:

1. Social dimension: The impact of the refrigeration and air-conditioning sector on the social dimension of sustainable development has numerous facets. The refrigeration sector employs more than 3 million people worldwide particularly in the industrial, commercial and service fields. Refrigeration is indispensable to human life. In the food sector, refrigeration contributes to reducing post-harvest losses and supplying safe, wholesome foods to consumers by enabling perishable foods to be preserved at all stages from production to consumption. In the health sector, refrigeration is employed for vaccine storage; cryo technology is used in surgery, superconductivity in scanners, etc.

2. Economic dimension: From an economic point of view, the role of refrigeration in many industrial processes and in cutting-edge technologies should be stressed. Refrigeration is necessary for the implementation of many current or future energy sources. Cryogenic processes make it possible to liquefy natural gas which is a more environmentally friendly energy source than other fuels. Many industrial processes could not operate without refrigeration.

3. Environmental dimension: The contribution of refrigeration to the environmental aspect of sustainable development is important as shown by the role of refrigeration technologies in maintaining biodiversity thanks to the cryopreservation of genetic resources (cells, tissues, and organs of plants, animals and microorganisms) in enabling the liquefaction of $\mathrm{CO}_{2}$ for underground storage and in making it possible to envisage the separation of $\mathrm{CO}_{2}$ from fossil fuels in power stations in the future. The impact of refrigeration is twofold due to atmospheric emissions of 
certain refrigerant gases used in refrigerating installations. These emissions arise due to leaks occurring in insufficiently leak-tight refrigerating installations or during maintenance-related refrigerant-handling processes and depending on the refrigerants concerned, can have an impact on ozone depletion (chlorinated refrigerants: CFCs and HCFCs) and/or global warming, by exerting an additional greenhouse effect (fluorinated refrigerants: CFCs, HCFCs and HFCs) (Chunfang et al. 2007).

The objective of the Kyoto Protocol, which entered into force in 2005, is to reduce emissions of six greenhouse gases in 39 developed countries, by at least $5 \%$ between 1990 and 2008-2012. HFCs are among these six greenhouse gases. Consequently, efforts implemented by refrigeration stake holders to combat global warming focus on two facets-reduction in direct emissions of fluorocarbons in the atmosphere thanks to better containment of refrigerants, refrigerant charge reduction and development of alternative refrigerants with negligible or no climate impact, reduction in energy consumption thanks to increasing energy efficiency of refrigerating plants; this is an important facet since the related global warming impact is four times higher than that of direct emissions.

\section{Conclusion}

Refrigerant selection based on a simple approach of 'zero ODP' will have to pay high cost to both global warming and energy efficiency. Use of this single criterion is no longer environmentally acceptable today.

The alarming increase in atmospheric concentration of HFC-134a suggested careful considerations of not overusing any single compound for substituting ODSs. The use of refrigeration will continue to expand worldwide, especially in developing countries, because it is vital to life. However, the environmental impacts, both on the ozone layer and on global warming are important. The refrigeration sector has already helped to mitigate global warming by applying the Montreal Protocol, also thanks to improved technologies and important international cooperation. The chemical industry is promoting new refrigerant it calls 'HydroFluoro-Olefins' or HFOs. Chemically, HFOs are HFCs, but due to the negative connotations that HFCs have acquired, this new class of chemicals has been marketed under a different name. This is part of a marketing strategy to portray these new HFCs as having a low impact on the climate while glossing over their negative environmental effects. DuPont and Honeywell's advertising point to car manufacturers is that it is a near drop in replacement to HFC-134a and does not require a complete MAC system redesign. $\mathrm{CO}_{2}$ on the other hand, operates at higher pressure so requires a new system with new components and tooling.

So selection of proper refrigerant is very important. One can select the particular refrigerant as per the application, the environmental and physiological properties and performance parameters. In this study it is suggested to phase out presently most used refrigerant R-134a considering global warming and to use natural refrigerants such as ammonia, carbon dioxide and hydro carbons in vapour compression refrigeration system for sustainable environment. HFO-1234yf can be used after all its tests are over and found suitable for refrigeration and air conditioning systems. Thermo-electric, magnetic and adsorption refrigeration are all eco-friendly technologies which are receiving more and more attention in the days of increasing energy and environmental problems. Adsorption refrigeration with a short study period can be used only in the condition of near room temperature.

Acknowledgments Vijay W. Bhatkar, Assistant Professor in Mechanical Engineering at Marathwada Mitra Mandals, Institute of Technology, Lohgaon, Pune, under University of Pune, Maharashtra, India, is thankful to Principal Dr. R. D. Kanphade, DPCOE Pune and Dr. B. P. Patil, Principal, MMIT Lohgaon, Pune for their constant support and motivation for writing this paper.

\section{References}

Awad MM, Mostafa HM, Sultan GI, Elbooz A, El-ghonemy AMK (2007) Performance Enhancement of Air-cooled Condensers. Acta Polytechnica Hungarica 4(2)

Bjorn P (2007) Refrigeration systems with minimum charge of refrigerant. Appl Therm Eng 27(9):1693-1701

Calm JM (2008) The next generation of refrigerants -Historical review, considerations and outlook. Int J Refrig 31:1123-1133

Cavallinia A, Censi G, Del Col D, Dorettia L, Longo GA, Rossetto L, Zilio C (2003) Condensation inside and outside smooth and enhanced tubes-a review of recent research. Int J Refrig 26(19):373-392

Chunfang Tanga, Qinghi Luob, Xiangmei Lib, Xiaojuan Zhua (2007). Refrigeration drives sustainable development, state of the art, 20th anniversary of the Montreal Protocol, 10th anniversary of the Kyoto Protocol, International Institute of Refrigeration (IIR)

Clito FA, Afonso (2006) Recent advances in building air conditioning systems. Appl Therm Eng 26(10):1961-1971

Daniel D (2007) Refrigeration selection considerations. University of Wisconsin, Industrial Refrigeration Consortium

Didier Coulomb, Director of the IIR (2008) Selection of refrigerants on a per application basis: trends, International Institute of Refrigeration, inter governmental organization for the development of refrigeration, new refrigerants. Int J Refrig 31:1121-1122

Emma C (2009) http://www.ClimateChangeCorp.co

Fernando P, Bjorn P, Ameel T, Lundqvist P, Granryd E (2008a) A minichannel aluminium tube heat exchanger-Part I: evaluation of single-phase heat transfer coefficients by the Wilson plot method. Int J Refrig 31:669-680

Fernando P, Palm B, Ameel T, Lundqvist P, Granryd E (2008b) A minichannel aluminium tube heat exchanger -Part III: condenser performance with propane. Int J Refrig 31:696-708 
Garcı-Cascales JR, Vera-Garcı F, Gonzalvez-Macia J, CorberanSalvador JM, Johnson MW, Kohler GT (2010) Compact heat exchangers modeling: condensation. Int J Refrig 33:135-147

Ge YT, Cropper RT (2009) Simulation and performance evaluation of finned-tube $\mathrm{CO}_{2}$ gas coolers for refrigeration systems. Appl Therm Eng 29:957-965

Gian Luca Morini (2004) Single-phase convective heat transfer in microchannels: a review of experimental results. Int J Therm Sci 43:631-651

Jama-Japia (2008) Consortium new refrigerants evaluation results, SAE, Alternative refrigerant systems symposium phoenix. Arizona USA

Jatuporn Kaew-On, Somchai W (2009) Experimental investigation of evaporation heat transfer coefficient and pressure drop of $\mathrm{R}-410 \mathrm{~A}$ in a multiport mini-channel. Int J Refrig 32:124-137

Kai W, Magnus E, Yunho H, Reinhard R (2010) Review of secondary loop refrigeration systems. Int J Refrig 33:212-234

Kenji T, Kazuaki T, Shigeo K (2009) Flammability assessment of $\mathrm{CH} 2 \mathrm{CFCF} 3$ : comparison with fluoroalkenes and fluoroalkanes. J Hazard Mater 172:1329-1338

Kondo S, Takizawa K, Takahashi A, Tokuhashi K, Mizukado J, Sekiya A (2009) Flammability limits of olefinic and saturated fluoro-compounds. J Hazard Mater 171:613-618

Minor B, Engineering Fellow, DuPont Fluoroproducts (2008) HFO1234yf Low GWP Refrigerant for MAC Applications, Mobile Air Conditioning Climate Protection Partnership Meeting, Dupont, Slide 1-33

Mohanraj M, Jayaraj S, Muraleedharan C, Chandrasekar P (2009) Experimental investigation of R290/R600a mixture as an alternative to R134a in a domestic refrigerator. Int $\mathrm{J}$ Therm Sci 48:1036-1042

Nasr MM, Salah Hassan M (2009) Experimental and theoretical investigation of an innovative evaporative condenser for residential refrigerator. Renewable Energy 34:2447-2454

Park CY, Hrnjak P (2008) Experimental and numerical study on microchannel and round-tube condensers in a R410A residential air-conditioning system. Int Inst Refrig (IIR) 31(10):822-831

Park HS, Punch J (2008) Friction factor and heat transfer in multiple microchannels with uniform flow distribution. Int J Heat Mass Transf 51:4535-4543

Pehlivan K, Hassan I, Vaillancourt M (2006) Experimental study on two-phase flow and pressure drop in millimeter-size channels. Appl Therm Eng 26:1506-1514

Perkins J (1834) Apparatus for producing ice and cooling fluids. patent 6662, UK

Philip CH Yu (2008) PhD RPE CEng, Member ASHRAE, Selection for sustainable future, Trane Asia Pacific
Poggi F, Macchi-Tejeda H, Leducq D, Bontemps A (2008) Refrigerant charge in refrigerating systems and strategies of charge reduction. Int J Refrigeration 31:353-370

Roshan GhR, Ranjbar F, Orosa JA (2010) Simulation of global warming effect on outdoor thermal comfort conditions. Int $\mathrm{J}$ Environ Sci Tech 7(3):571-580

Rotchana P (2009) Development of an assessment method for refrigerant performance comparison, SIRAC meeting, at UCL

SAE International (2008) SAE CRP1234 Industry Evaluation of low global warming potential refrigerant HFO1234yf. http://www.epa. gov/ozone/snap/fire/co2/co2report.pdf

Shenzhen (2006). Comparison of several eco-friendly refrigeration technologies, ICEBO 2006, China renewable energy resources and a greener future, Vol. VIII

Shigeo K, Kenji T, Akifumi T (2009) Kazuaki Tokuhashi. Junji Mizukado, Akira Sekiya

Spatz Mark W (2009) HFO -1234 yf technology update-part II. Global leader refrigerant technology, Honeywell

Spatz Mark, Honeywell Barbara Minor, DuPont (2008) HFO1234yf-A low GWP refrigerant for MAC-SAE World Congress-Detroit, Michigan

Steven Brown J, Zilio C, Cavallini A (2010) Thermodynamic properties of eight fluorinated olefins. Int J Refrig 33:235-241

Tanaka K, Higashi Y (2010) Thermodynamic properties of HFO1234yf (2,3,3,3- tetrafluoropropene). Int. J. of Refrigeration 33(3):474-479

Tony B (2001) Manufacturing heat exchangers with extruded aluminium tube, ASHRAE

UNEP (2000) International Institute Refrigeration, Refrigeration drives sustainable development, Report of the Technology and Economic Assessment Panel, Nairobi

Wei L, Zan W (2010) A general criterion for evaporative heat transfer in micro/mini-channels. Int J Heat Mass Transf 53:1967-1976

Yeon-Pun C, Rueyyih T, Jiin-Wen H (1997) Condensing heat transfer characteristics of aluminum flat tube. Appl Therm Eng 17(11):1055-1065

Yun Rin, Heo Jae Hyeok, Kim Yongchan (2006) Evaporative heat transfer and pressure drop of R410A in microchannels. Int $\mathrm{J}$ Refrig 29:92-100

Zhaogang Q, Jiangping C, Reinhard R (2009) Investigating performance of new mini-channel evaporators. Appl Therm Eng 29:3561-3567

Zhaogang Q, Zhao Y, Jiangping C (2010) Performance enhancement study of mobile air conditioning system using micro channel heat exchangers. Int J Refrig 33:301-312 